\title{
INVESTIGATION AND MODELLING OF EDM PROCESS PARAMETERS IN MACHINING OF INCOLOY-800
}

\author{
Harmanpreet $^{1}$, Harvinder Lal ${ }^{2}$, Gaurav Dhuria ${ }^{3}$ \\ ${ }^{I}$ M.Tech student, Production Engineering, RIET, Phagwara, India \\ ${ }^{2}$ Assistant Prof. Mechanical department, RIET, Phagwara, India \\ ${ }^{3}$ Associate Prof. and Head, ME Dept., DAVIET, Jalandhar, India
}

\begin{abstract}
The experimentation has been performed on EDM for the modelling and optimization of the process parameters. In this work modelling of the processes are done by artificial neural networking and optimization by genetic algorithm. For fitness function regression analysis has been performed. Design of experiment with mixed level $L_{18}$ orthogonal array has been considered. All 18 experiments were performed on INCOLOY-800. Copper as an electrode considered. In this work TWR considered as the response variable. Dielectric fluid with two level; where current, pulse on time and gap voltage considered with three levels as the process parameters. 4-17-1-1 network considered in ANN by feed forward back propagation for process modelling. Two types of dielectric fluid considered as kerosene and EDM oil. For multi objective-optimization Genetic Algorithm used (GA).
\end{abstract}

Keywords -Artificial neural network, genetic algorithm, machining time, material removal rate $* * *$

\section{INTRODUCTION}

Electrical discharge machine is one of the modernized machine used to cut hard material. Its basic principle based on thermal and conductivity property of the work material and tool. . The process occur between tool and a work material in the presence of a die-electric fluid. Two Russian scientists B. R. and N. I. Lazarenko invented the electronic circuit which was known as relaxation circuit. In this circuit machining was formed by using a servo controller. The servo controller maintained the gap width between the tool and the work piece material. The principle of electrical discharge machining (EDM) is to use the eroding effect for the controlled electric spark discharges on the electrodes by the variation of the pulse. It is thus a thermal erosion process. Due to presence of dielectric fluid in between the work piece and electrode the electric spark is generated in it. The sparks are created in a dielectric liquid, generally water or oil, between the work piece material and the cutting tool or also known as electrode. There is no mechanical contact between the electrodes during the whole machining process. Since erosion is produced by electrical discharges, so both electrode tool and work piece material have to be a good conductor of electricity for the spark generation during the machining process [1]. Metal material removal takes place as a result of the generation of extremely high temperatures generated by the highly intensify discharges that melt and evaporates the electrodes material.

\section{LITERATURE REVIEW}

E. Aliakbari and H. Baseri performed the Optimization of machining parameters in rotary EDM. In this process taguchi method was considered [3]. In this study the surface finish was improved by rotating the tool. The optimal rotating parameters of the tool were performed. A good surface finish was attained in it [3]. P.M. George et al worked on the EDM machining of carbon-carbon composite by using a taguchi approach [4]. In this there objective was to determine the optimal setting of the process parameters on the electro-discharge machining (EDM) while machining carbon-carbon composites. Qualitek-4 software was used to apply taguchi method. It has been shown that machining parameters set at their optimum levels can ensure significant improvement in the response functions [4]. Tzeng and chenin 2013 studied the optimization of EDM process. In the investigation response surface methodology and genetic algorithm was used for modelling and optimization. The back propagation neural network/GA gives better prediction results in the experimental runs in the experimental runs than regression models based on the RSM method [5].Atefi et al in 2012 investigated for EDM parameters in finishing stage on surface quality. Hybrid model was considered. A hybrid model, combination of statistical analysis and ANN, is designed to reduce the error in optimization of complex and non-linear problems [6]. Bharti et al in 2012 performed multi-objective optimization of electric-discharge machining process using controlled elitist NSGA-II. The average percentage difference between experimental and ANN's predicted value was 4 and 4.67 for MRR and SR respectively [7]. Andromeda et al in 2011 performed for Predicting Material removal rate (MRR) of EDM. Artificial neural network for high I gap current. The capability of ANN to follow the dynamical behaviour of the EDM process is not precisely accurate [8].Mahdavi Nejad and R.A. (2001) studied modelling and optimization of EDM of Sic Parameters using ANN and Non-dominating Sorting Genetic Algorithm (NSGA II). ANN with Back propagation algorithm is used to model the process. MRR and SR are optimized as objectives by using NSGA II [9]. Agrawal A et al 2013 performed modelling and optimization of tool wear 
rate in powder mixed EDM of MMC. Mixing graphite powder in dielectric significantly reduces the TWR during machining of MMC. The peak current has been identified as most significant control factor affecting TWR, followed by powder concentration. In this the developed ANN model is reliable and adequate to predict the TWR with negligible prediction error. [10]. Tsai and Wang Predicts on surface finish in electric discharge machining (EDM) based upon neural network models. The comparison on predictions of surface finish for various work materials based upon six different neural networks models and a neuro-fuzzy network model is illustrated [11].Su et al (2004) investigated for optimization of the electrical discharge machining process using a GA-based neural network. The developed neural network with the aid of a GA has sufficient prediction and reasoning capability to genetic optimal process parameters from rough cutting stage to finish cutting stage [12].Pragya Shandilya in 2014 studied modelling and optimization for WEDM processes. Kerf width as response was considered. 200 generation rate, population size as 100 , no. of stall generation as 50 were considered in GA. Kerf with was reduced from 0.261 to 0.245 by genetic algorithm. Minimization in kerf width was set in GA fitness function. $2.39 \%$ predicted values were set for getting the required output [13].Neeraj Sharma in 2014 investigated for WEDM process variables. Two techniques RSM and GA were considered in the investigation. GA was used for optimization and RSM were used for mathematical modelling. For dielectric temperature were maintained at 35 ${ }^{0}$ c. Cutting voltage at 80V. 2050units for servo feed. Central composite design with 32 experiments were considered. With the RSM lower and upper bond were defined and controlled. Cross over fraction set at 0.8. Mutation as uniform identity were set in it. It was concluded that the result obtained after applying GA were good. The value of R2 was achieved at 0.9863 [14]. A. Varun et al in 2015 studied the process parameters by GRA with GA. Experiments were performed on the EN 353 as the work material. Face centered central composite design were preferred for experimentation. It was observed that with rise in current discharge energy also increases. With GRA the results can be generated within the experimental values [15]. V. Balasubramaniam in 2014 performed on the Optimization and modelling of EDM Parameters Using ANN with different electrodes. Investigation shows that current is the most significant parameters. Among the three different electrodes copper yields better performances. Machining time also reduces with better performances [16]. Dragan Rodic and Marin Gostimirovic in 2014 associated for the optimization and modelling technique of Fuzzy logic and neural network for modelling Surface Roughness (SR) in EDM. Both fuzzy logic and neural network were implemented for comparison. The results indicates that the NN model is an effective algorithm to predict the surface roughness in electrical discharge machining (EDM). The effectiveness of the models was only within the ranges and aspects studies [17]. In 2014 Yunn- Shiuan Liao et al studied the machining behaviour and parameters for the optimization of WEDM. Ti6Al4V (Ti alloy) and SUS304 (Stainless steel) as work material selected. L18 orthogonal array was selected for DOE with three level design. 8-15-5 network was created in the nntool. 0.5 As learning rate and 0.5 as momentum of coefficient was considered in neural network. For the optimization GA approach was performed. With the GA technique combination of the machining parameters were successfully achieved. Due to which machining time and cost factors get improved [18]. In 2014 G.Ugrasen et al studied the estimation of machining performance of wire EDM. EN31 was considered as the work piece and molybdenum as tool material. MRA, GMD and ANN techniques were used for modelling of the network. Reuse of the wire was performed on four axes CNC WEDM (CONCORD DK7720c). Back propagation feed forward neural network (BPNN) and LevenbergMarquardt algorithm (LMA) were used for creating network. So it was observed that ANN function performed better predicted results than MRA and GMDH [19].

\section{EXPERIMENTATION SETUP}

The experiments were conducted on OSCAR MAX S-645 EDM machine as shown in figure 1. Design of experiment was performed in Minitab software for mixed level design.18 experiments were conducted on the EDM. Experiments were conducted on Incoloy-800 as work material of square shape $(25 \mathrm{~mm} \times 25 \mathrm{~mm} \times 8 \mathrm{~mm})$ imported from japan. $99.8 \%$ pure Copper as an electrode considered ( $12 \mathrm{~mm}$ diameter and $15 \mathrm{~mm}$ in length). Four controlled parameters were considered namely Current, gap voltage, pulse on time and dielectric fluid. MRR and machining time as response parameters. Two types of EDM dielectric fluid considered were kerosene and EDM oil (ferrolac 3m edm oil). All the experiments were performed at constant dielectric fluid temperature $\left(30^{\circ} \mathrm{c}\right)$.

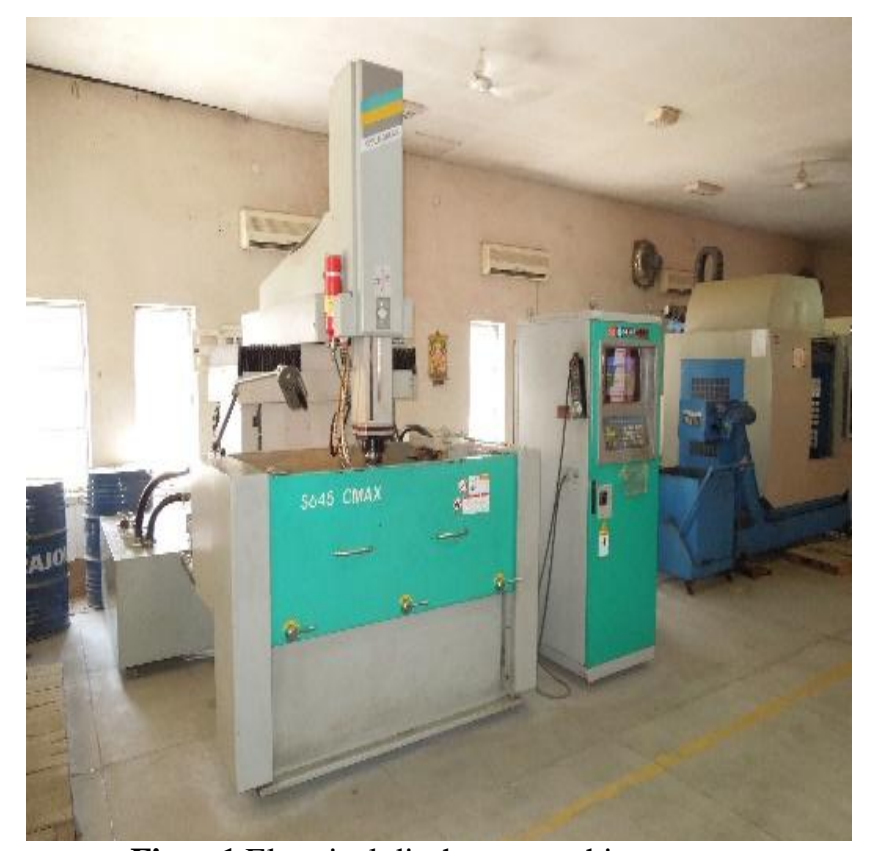

Fig: - 1 Electrical discharge machine setup 


\subsection{Material used for Experiments}

Table: - 1 Material used in experimentation

\begin{tabular}{|l|l|l|}
\hline Material used & Type \\
\hline Work Material & INCOLOY-800 & \\
\hline Tool Material & COPPER & \\
\hline Dielectric fluid & $\begin{array}{l}\text { Ferrolac } \\
\text { EDM oil }\end{array}$ & Kerosene \\
\hline
\end{tabular}

\subsection{Experimental Design of Experiments with}

\section{Levels}

On the basis of literature review design of the experiment has been selected. $\mathrm{L}_{18}$ orthogonal array with mixed level design has been considered. For DOE Minitab statistical software version 17 used. There are 18 experiments with single run. All the experiments were studied by applying electrode as positive polarity and work material as negative polarity. In the experiment the pulse off time was kept constant at $30 \mu \mathrm{s}$. where flushing pressure was also kept constant at $0.5 \mathrm{~kg} / \mathrm{cm}^{2}$. Depth of cut for all experiments were taken as $1 \mathrm{~mm}$.two levels for dielectric fluid and three levels for current, pulse on time and gap voltage considered.

Table:-2 Machining parameters and there levels

\begin{tabular}{|c|c|c|c|c|c|}
\hline \multirow{2}{*}{$\begin{array}{l}\text { Input } \\
\text { process } \\
\text { parameters }\end{array}$} & \multirow{2}{*}{$\begin{array}{l}\text { Sym } \\
\text { bol }\end{array}$} & \multirow[t]{2}{*}{ Units } & \multicolumn{3}{|c|}{ Levels } \\
\hline & & & 1 & 2 & 3 \\
\hline $\begin{array}{l}\text { Dielectric } \\
\text { fluid }\end{array}$ & $\mathrm{A}$ & -- & $\begin{array}{l}\text { EDM } \\
\text { oil }\end{array}$ & $\begin{array}{l}\text { Kerosen } \\
\text { e oil }\end{array}$ & -- \\
\hline Current & B & Amp & 14 & 18 & 22 \\
\hline $\begin{array}{l}\text { Pulse on } \\
\text { time }\end{array}$ & $\mathrm{C}$ & $\mu \mathrm{s}$ & 30 & 45 & 60 \\
\hline Gap Voltage & $\mathrm{D}$ & $\mathrm{V}$ & 12 & 14 & 16 \\
\hline
\end{tabular}

Table:-3 Experimental data considered for design

\begin{tabular}{|l|l|l|l|l|l|}
\hline $\begin{array}{l}\text { Sr. } \\
\text { No }\end{array}$ & A & B & C & D & $\begin{array}{l}\text { TWR } \\
(\mathbf{m m} / \mathbf{m i n})\end{array}$ \\
\hline 1 & 1 & 1 & 1 & 1 & 17.93 \\
\hline 2 & 1 & 1 & 2 & 2 & 6.66 \\
\hline 3 & 1 & 1 & 3 & 3 & 2.79 \\
\hline 4 & 1 & 2 & 1 & 1 & 48.11 \\
\hline 5 & 1 & 2 & 2 & 2 & 32.98 \\
\hline 6 & 1 & 2 & 3 & 3 & 18.37 \\
\hline 7 & 1 & 3 & 1 & 2 & 58.3 \\
\hline 8 & 1 & 3 & 2 & 3 & 51.42 \\
\hline 9 & 1 & 3 & 3 & 1 & 43.24 \\
\hline 10 & 2 & 1 & 1 & 3 & 16.91 \\
\hline 11 & 2 & 1 & 2 & 1 & 13.33 \\
\hline 12 & 2 & 1 & 3 & 2 & 6.99 \\
\hline
\end{tabular}

\begin{tabular}{|l|l|l|l|l|l|}
\hline 13 & 2 & 2 & 1 & 2 & 38.87 \\
\hline 14 & 2 & 2 & 2 & 3 & 31.71 \\
\hline 15 & 2 & 2 & 3 & 1 & 26.34 \\
\hline 16 & 2 & 3 & 1 & 3 & 49.75 \\
\hline 17 & 2 & 3 & 2 & 1 & 50.05 \\
\hline 18 & 2 & 3 & 3 & 2 & 40.54 \\
\hline
\end{tabular}

\subsection{Material Investigation Equipment's}

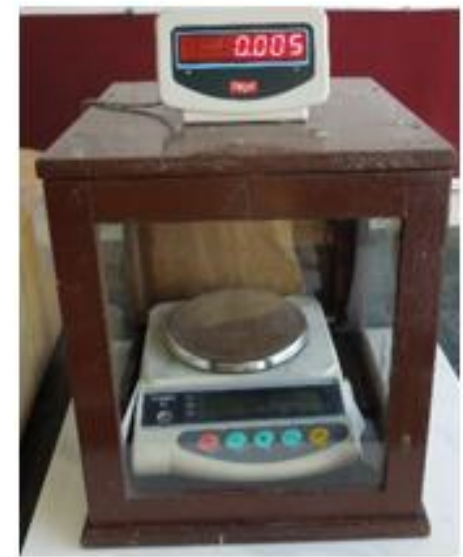

Fig: - 2 Weighing machine

ViBRA AJ machine for weighing has been considered as shown in figure 2. Maximum capacity for weighing in this machine is $220 \mathrm{~g}$ and least count is $1 \mathrm{mg}$. the main objective for considering this machine is to get accurate MRR and TWR. Three trial were performed for error reduction. With three trials more accuracy achieved.

\section{MODELLING BY ARTIFICIAL NEURAL NETWORK}

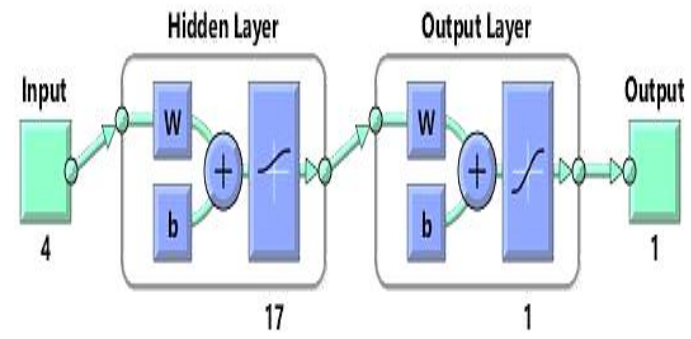

Fig:-3 Network topology

An artificial neural network is a mathematical functions used to predict the data. In this experimental analysis ANN is applied for modelling of the process parameters. The network have four inputs with two output value. MATLAB (R2014a version 8.3.0.532) software considered for ANN for modelling processes. Intel core-i5 processor $3.10 \mathrm{GHz}$ turbo booster with 5GB RAM considered for fast processing and quick response. MRR and machining time were considered as the target. 4-17-1-1 network created by considering feed forward neural network with back 
propagation. The number of neurons were considered by trial and error method [2]. For network training learning rate at 0.001and momentum as 0.01. Levenberg-Marquardt method used for training data. For performance objective mean square error (MSE) considered.
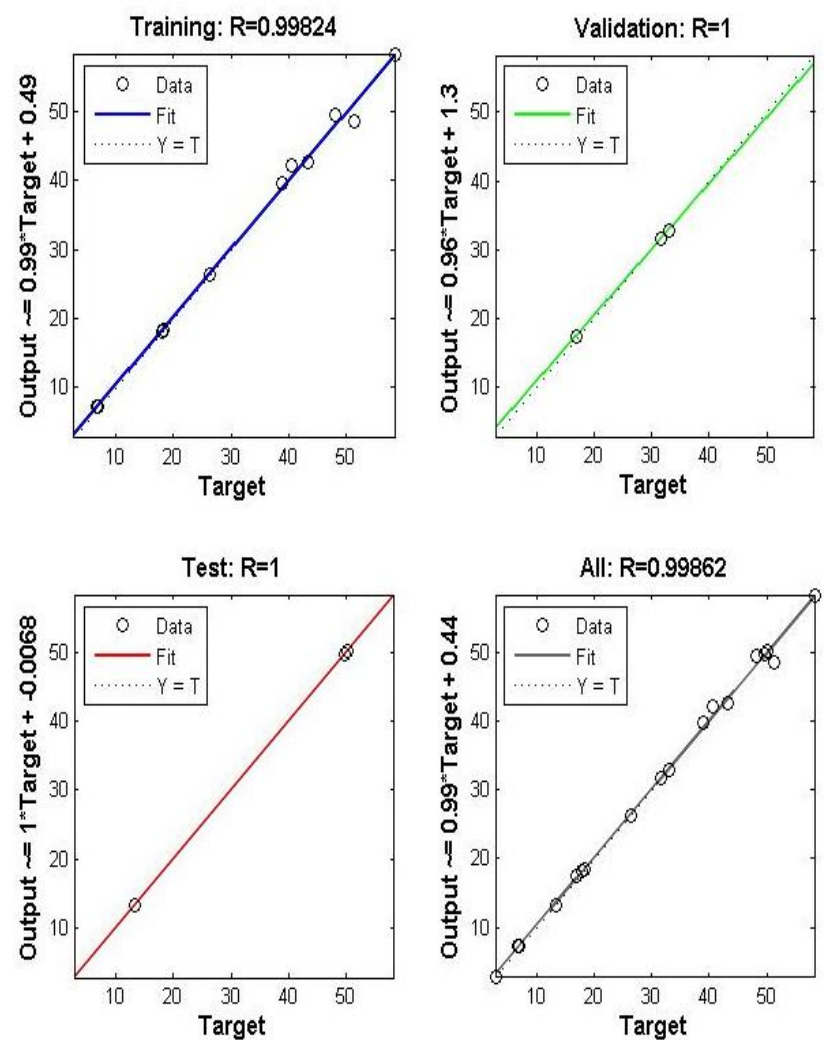

Fig:- 4 Regression graph

Table 4:-ANN prediction results

\begin{tabular}{|l|l|l|}
\hline $\begin{array}{l}\text { Experimental } \\
\text { values }\end{array}$ & $\begin{array}{l}\text { ANN } \\
\text { prediction }\end{array}$ & Error \\
\hline 17.93 & 18.13835659 & -0.208356587 \\
\hline 6.66 & 7.351982525 & -0.691982525 \\
\hline 2.79 & 2.791220787 & -0.001220787 \\
\hline 48.11 & 49.59318426 & -1.483184259 \\
\hline 32.98 & 32.84687894 & 0.133121058 \\
\hline 18.37 & 18.43971085 & -0.069710852 \\
\hline 58.3 & 58.29747995 & 0.002520049 \\
\hline 51.42 & 48.55937078 & 2.860629218 \\
\hline 43.24 & 42.70017467 & 0.539825331 \\
\hline 16.91 & 17.49141752 & -0.581417524 \\
\hline 13.33 & 13.33835648 & -0.008356476 \\
\hline 6.99 & 7.334462889 & -0.344462889 \\
\hline 38.87 & 39.68806464 & -0.818064642 \\
\hline 31.71 & 31.66774946 & 0.042250544 \\
\hline 26.34 & 26.36876586 & -0.02876586 \\
\hline 49.75 & 49.7597666 & -0.009766596 \\
\hline 50.05 & 50.13720054 & -0.087200543 \\
\hline 40.54 & 42.21935719 & -1.679357191 \\
\hline & &
\end{tabular}

\section{GENETIC ALGORITHM OPTIMIZATION}

The objected has been subjected to the GA tool box of MATLAB (8.3.0.532 Version R2014a). All the parameters were considered by inserting them in GA fitness function. The bounds were set for lower limits and upper limits. The number of variables were considered as 4 . The objective subjected to minimize TWR.

Objective:-

Minimize --- TWR

$1 \leq$ Dielectric fluid $\leq 2$

$14 \leq$ Current $\leq 22$

$30 \leq$ Pulse on time $\leq 60$

$12 \leq$ Gap voltage $\leq 16$

For GA the population size as 50, number of generation 100 , fitness scaling top at 0.4 , creation function as constraint dependent with initial range [-10,10], selection function Stochastic uniform, for reproduction crossover fraction as 0.8, mutation as adaptive feasible, crossover two point function, migration forward with 0.2 fraction rate, stopping criteria at 100 number of variation, stall generation at 100 . After applying these criteria the optimum solution obtained in table 5. Figure 6 define the genetic generation and pareto front graph.

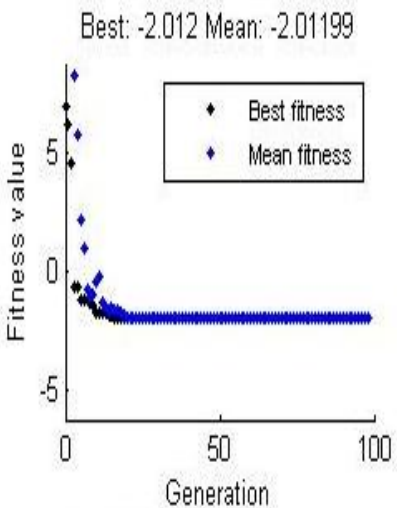

Average Distance Between Individuals

Best, Worst, and Mean Scores
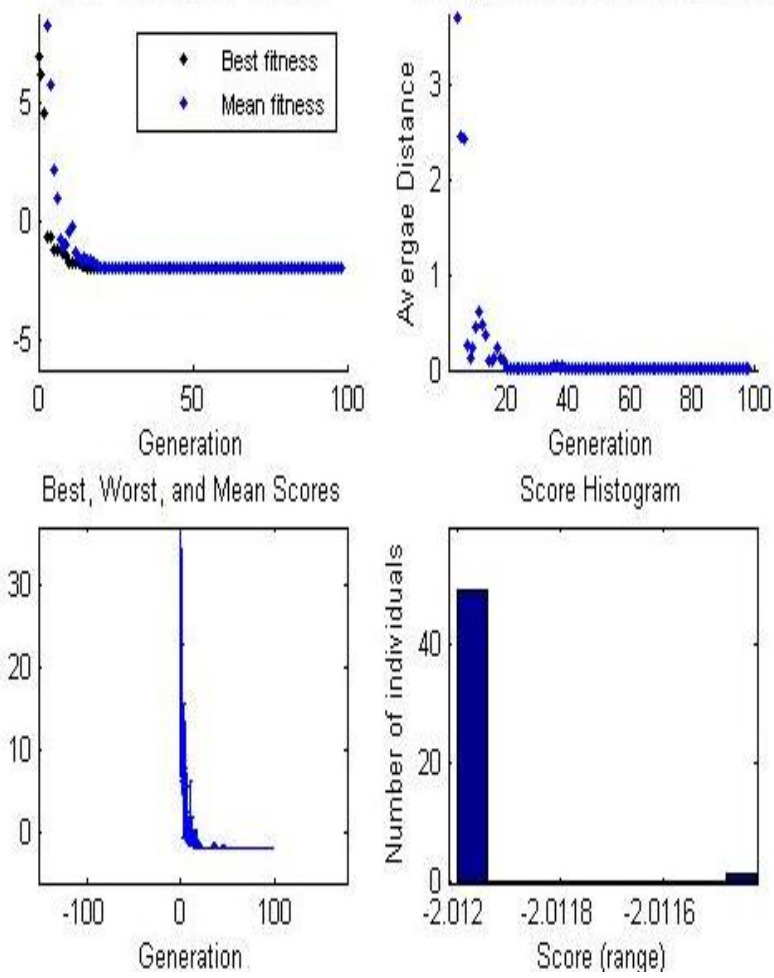

Score Histogram

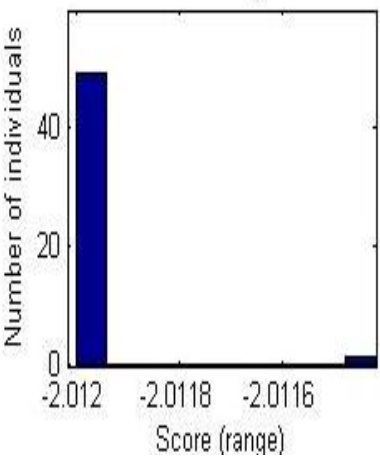

Fig: - 6 Pareto and generation plot

Table: - 5 Optimum values for process parameters

\begin{tabular}{|l|l|l|l|l|}
\hline A & B & C & D & $\begin{array}{l}\text { TWR } \\
(\mathbf{m m} / \mathbf{m i} \\
\mathbf{n})\end{array}$ \\
\hline 2 & 14 & 60 & 16 & 2.01199 \\
\hline
\end{tabular}




\section{RESULT AND CONCLUSION}

In this work design of experiment considered as with mixed levels $\mathrm{L}_{18}$ orthogonal array. Table 2 define the design of experiment. Where table 3 define the experimental response values. The present study performed by modelling of the process by artificial neural networking (ANN). After modelling of the processes the optimization done by genetic algorithm (GA). Figure 3 defines the network topology for the ANN. In this work with high accuracy error prediction performed in ANN as shown in table 4. A good output result obtained by ANN. The maximum error predicted by ANN with experimental values in TWR $2.860629218 \mathrm{~mm}$. As shown in figure 4 it represents the regression graph training data $99.824 \%$, test data $100 \%$, validation data $100 \%$ and over all data $99.862 \%$. All the data obtained at best fits. In figure 5 performance curve defined between training, test and validation. Low mean square error (MSE) obtained. By statistical point of view $\mathrm{R}$ should be obtained greater or equal to $95 \%$. In this work the results obtained were at 99.9\% accuracy which result with very low error rate. Further for optimization gatool used in MATLAB. With GA optimum values obtained. Optimum results obtained as shown in table 5. Low TWR at $2.01199 \mathrm{~mm} / \mathrm{min}$. In GA for dielectric fluid Kerosene oil, current 14, pulse on time 60 and gap voltage 18 attained for having optimum solutions. With this study the cutting condition was validated to achieve optimum processes.

\section{ACKNOWLEDGEMENTS}

The authors would like to acknowledge the support from the parent's and those who contributed directly or indirectly are thanked. My deeply thanks also goes to others who have provided assistance at various occasions that invite whether direct or indirectly in the completion of this journal.

\section{REFERENCES}

[1] Harpreet singh, Amandeep singh "Effect of Pulse On/Pulse off Time on Machining of Aisi D3 Die Steel Using Copper and Brass Electrode in Edm" IJES, Vol 1, issue 9, November 2012.

[2] P. G. Benardos and G. C. Vosniakos, "predicting surface roughness in machining: A review," international journal of machine tools and manufacturing, vol. 43, no. 8, pp. 833-844, 2003.

[3] E. Aliakbari. H. Baseri, "Optimization of machining parameters in rotary EDM process by using the taguchi method", Springer, January 2012, 1041-1053.

[4] P.M. George ${ }^{a,{ }^{*}}$, B.K.Raghunath ${ }^{\mathrm{b}}$, L.M.Manocha ${ }^{\mathrm{c}}$, Ashish M.Warrierc, "EDM machining of carboncarbon composite- a taguchi approach", Elsevier, 2003, 66-71.

[5] Tzeng, C.J.; chen, R.Y (2013) optimization of electric discharge machining process using the response surface methodology and genetic algorithm approach. International journal of precision engineering and manufacturing, 14(5): 709-717.

[6] Atefi, r.; Razmavar, A.; Teimoori, F.; Teimoori, F. (2012) the investigation of EDM parameters in finishing stage on surface quality using Hybrid model. Journal of basic and applied scientific rsearch, 2(3): 3061-3065.

[7] Bharti, P.s.; Maheshwari, S.; Sharma, C. (2012) multi-objective optimization of electric-discharge machining process using controlled elitist NSGA-II. Journal of mechanical science and technology, 26(6): 1875-1883.

[8] Andromeda, T.; Yahya, A.; Hisham, N.; Khalil,K.; Erawan, A.;(2011) Predicting Material removal rate of electrical discharge machining (EDM) using artificial neural network for high I gap current. International conference on electrical, control and computer engineering, IEEE, 21-22 june, Pahang, Malaysia.

[9] MahdaviNejad, R.A. (2001) Modeling and optimization of electrical Discharge Machining of Sic Parameters, using Neural Network and Nondominating Sorting Genetic Algorithm (NSGA II). Materials Sciences and Applications, 2(6): 669-675.

[10] Agrawal A., Dubey, A. K., \&Shrivastava, P.K. (2013) "Modeling and optimization of tool wear rate in powder mixed EDM of MMC", $2^{\text {nd }}$ International conference on Mechanical and Robotics Engineering (ICMRE2013) Dec. 17-18, 2013 Pattaya (Thailand).pp.1-6.

[11] Tsai, K.M.; Wang, P.J. (2001) "Predictions on surface finish in electric discharge machining based upon neural network models", international journal of machine tools and manufacture, 41(10), 13851403.

[12] Su, J.C; Kao, J.Y; Tarng, Y.S (2004) “optimization of the electrical discharge machining process using a GA-based neural network", the international journal of advance of advance manufacturing technology, 24 (1-2), 81-90.

[13] Pragya Shandilya, Abhishek Tiwari (2014), "Artificial neural network modeling and optimization using genetic algorithm of machining process", Journal of automation and control engineering, Vol. 2, No. 4, pp. 348-352, DOI: $10.12720 /$ joace.2.4.348352.

[14] Neeraj Sharma, Rajesh Khanna, Rahul Dev Gupta (2014), "WEDM process variables investigation for HSLA by response surface methodology and genetic algorithm", Engineering science and technology, an international journal, pp. 1-7, DOI: 10.1016/j.jestch.2014.11.004.

[15] A. Varun, NasinaVenkaiah (2015), "Simultaneous optimization of WEDM responses using grey relational analysis coupled with genetic algorithm while machining EN 353", International journal of advance manufacturing and technology, pp. 675-690, DOI: $10.1007 / \mathrm{s} 00170-014-6198-4$.

[16] V. Balasubramaniam, N.Baskar, C.Sathiya Narayanan, "Optimization of Electrical Discharge Machining Parameters Using Artificial Neural Network With Different Electrodes", AIMTDR, pp. 152-156, 2014. 
[17] Dragan Rodic, Marin Gostimirovic, Pavel Kovac, Miroslav Radovanovic, BorislavSavkovic,

Comparison of Fuzzy logic and neural network for modelling Surface Roughness in EDM", IJMECH, Vol.3, No.3, pp.69-78, 2014.

[18] Yunn-ShiuanLaio, Tzung-Jen Chuang, Young-ping $\mathrm{Yu}$, "study of machining parameters optimization for materials in wedm", international journal of advance manufacturing and technology, pp. 2051-2058, 2014.

[19] G. Ugrasen, H.V. Ravindra, G.V. Naveen Prakash, R.Keshavamurthy, "Estimation of machining performance using MRA, GMDH and Artificial neural network in wire EDM of En31", $3^{\text {rd }}$ international conference on materials processing and characterization, procedia materials science, pp. 1788-1797, 2014.

\section{BIOGRAPHIES}

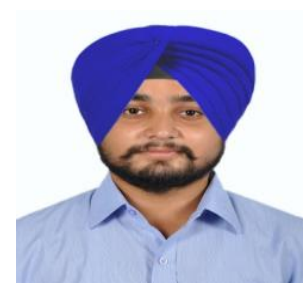

Harmanpreet* received his B.Tech degree in Mechanical Engineering from DAV Institute of Engineering and Technology, Punjab Technical University, Jalandhar, India in 2012. M.Tech degree in Production Engineering from Ramgarhia Institute of Engineering and Technology, Phagwara, India from Punjab Technical University in 2015. He has published two journals and three journals are under process.

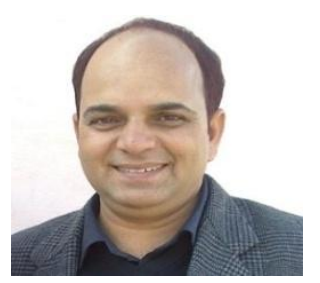

Harvinder Lal received his B.Tech degree from GZSCT, Bathinda, India, in 1997. M.Tech Degree from Dr. B.R. Ambedkar NIT, Jalandhar, India, in 2012. He has more than 15 years of experience in industry and teaching of graduate and postgraduate students. He is having more than 10 research papers to his credit. He is presently Head of mechanical department in RIET, Phagwara. India.

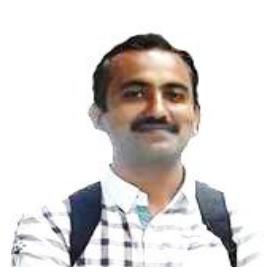

Gaurav Dhuria Received his B.Tech degree and M.Tech degree from Punjab Technical University, Jalandhar, India in mechanical engineering. $\mathrm{He}$ is presently Associate Professor and Head of mechanical department of DAV institute of engineering and technology, Jalandhar, India. 